ISSN: 0210-7287

DOI: https://doi.org/10.14201/161620211199116

\title{
COPLAS FLAMENCAS SUELTAS Y POEMAS DEL CANTE COMPUESTO: DOS MOLDES DISTINTOS DE LAS LETRAS DEL CANTE, ENTRE TEXTOS TRADICIONALES Y TEXTOS DE NUEVA CREACIÓN
}

\author{
Autonomous Flamenco Coplas and Whole Poems \\ of Composed Cantes: Two Different Forms of Flamenco \\ Song Texts, between Traditional and New Lyrics
}

Florian HOMANN

Universidad de Münster

fhomann@uni-muenster.de

Recibido: 01/12/2019; Aceptado: 01/04/2020; Publicado: 31/12/2021

Ref. Bibl. FLORIAN HOMANN. COPLAS FLAMENCAS SUELTAS Y POEMAS DEL CANTE COMPUESTO: DOS MOLDES DISTINTOS DE LAS LETRAS DEL CANTE, ENTRE TEXTOS TRADICIONALES Y TEXTOS DE NUEVA CREACIÓN. 1616:

Anuario de Literatura Comparada, 11 (2021), 99-116

RESUMEN: Las letras flamencas se suelen analizar como unidades aisladas, a nivel de copla suelta. Escasamente se ha considerado el conjunto de las estrofas que emplea un cantaor en una ocasión determinada y en un orden concreto. Este artículo añade a la existente concepción de la copla flamenca una nueva unidad de sentido, que es el poema del cante compuesto. Los ejemplos analizados de letras flamencas indican la conveniencia de trabajar en ambas dimensiones. Resulta fructífero comprobar si se establece en un cante una relación entre las distintas estrofas, para prestar un nuevo enfoque en el tratamiento de las letras por los cantaores, que se convierten en coautores del texto que surge gracias a su selección y reestructuración de los elementos literarios. Así, se tejen 
continuamente nuevas redes intertextuales en los cantes en performance, por lo que los significados de las coplas pueden variar en cada ocasión, según el contexto correspondiente.

Palabras clave: copla flamenca; copla suelta; performance flamenca; letras del cante flamenco; poesía lírica; poesía narrativa.

ABSTRACT: Flamenco coplas have been previously examined only on the level of separate entities. This paper contributes a new conception to this one of the autonomous copla suelta. The so called poem of a composed cante describes a different unit of meaning, as the result of a set of various single verses, restructured in a particular order by the flamenco singers in performance. It is especially meaningful to check whether there is a relationship between the different literary elements that are used to compose the whole musical unit. The examples of analysed flamenco lyrics show the advantages of working at both of these levels. So there is a new focus on flamenco singers who really become co-authors of these texts that come into being from their selection and restructuring of single verses. Unique intertextual tissues emerge continuously, which also indicates that the meaning of any flamenco copla can be different in every divergent circumstance and context.

Key words: flamenco copla; autonomous copla; flamenco performance; lyrics in flamenco singing; lyrical poetry; narrative poetry.

\section{INTRODUCCIÓN: EL FLAMENCO Y SUS LETRAS ${ }^{1}$}

El flamenco es una cultura que se define en alto grado por aspectos musicales. A pesar de que sus letras, en el sentido de soportes literarios de los cantes, están subordinadas a la música, la poesía del flamenco también llega a ser considerada un patrimonio cultural de considerable interés. Se suele destacar su transmisión de boca en boca durante un largo lapso de tiempo, por lo que las letras flamencas se caracterizan a través de los rasgos típicos de una auténtica tradición oral.

1. Esta investigación se ha realizado en el marco de un proyecto de tesis doctoral, en la Universidad de Colonia en cotutela con la Universidad de Sevilla, con una estancia en Sevilla desde octubre de 2017 hasta abril de 2018, gracias a una beca del DAAD (German Academic Exchange Service). 
El interés por las letras del flamenco despertó cuando Antonio Machado y Álvarez (1996) presentó en 1881 su colección de cantes flamencos². Los primeros acercamientos a los textos poéticos se realizaron a continuación por diversos poetas e intelectuales antes de que, en la década de 1960, Molina y Mairena publicaran Mundo y formas del cante flamenco, que durante muchos años sería considerada "la biblia del flamenco" (Vergillos 2002, 13), y que contiene un capítulo sobre el universo espiritual de las letras flamencas (Molina y Mairena 2004, 99-138). A pesar de que muchas ideas expuestas en este libro han sido superadas actualmente, la obra todavía ejerce una influencia considerable sobre el mundo flamenco.

A finales del siglo Xx, la investigación del flamenco entra en su "fase científica de la flamencología crítica» (Steingress 1993, 100), generándose muchos estudios profundos. Con respecto a las letras, la tesis doctoral de Gutiérrez Carbajo (1990) marca un hito.

Es llamativo que se suelen analizar casi en exclusivo las coplas escritas en los cancioneros. Entre las muchas antologías que se publicaron durante el siglo Xx, destaca la colección de poesía flamenca de Fernández Bañuls y Pérez Orozco (2004), publicada aproximadamente cien años más tarde que la de Demófilo, en 1983, con una reedición en el siglo XxI. Esta suele ser la fuente para muchos trabajos de investigación.

Además, a partir de estas fechas, se vuelve a examinar la relación entre el romancero y determinadas modalidades del cante, siendo la aportación más esclarecedora la de Suárez Ávila (1989). Hay consenso en que existe cierta dificultad a la hora de reconocer como romances muchos textos del repertorio de los cantaores, debido a que estos suelen ser extremadamente fragmentados.

Piñero, al reconocer la vivacidad y la importancia de estos poemas orales para el ámbito académico, se posiciona a favor de estudiar las letras del cante como un tipo específico de poesía tradicional con la profundidad que merece: «Es muy probable que sea la flamenca una de las más ricas y vivas modalidades de la lírica popular del ancho mundo panhispánico, y ya es hora de que se la considere como tal, al mismo nivel que otras manifestaciones de la canción tradicional» (2004, 10). Este camino ya está iniciado.

2. El término cante y las clasificaciones de las distintas modalidades del mismo se refieren a aspectos de naturaleza musical; no obstante, Demófilo (MACHADO 1996, 78) los declaró un "género poético, predominantemente lírico». Se nota cierta contradicción, teniendo en cuenta que Demófilo ordenó sus coplas principalmente según la música en las que las escuchó, sin seguir este criterio consecuentemente. 
En los últimos años se han publicado múltiples investigaciones sobre la poesía lírica del cante ${ }^{3}$.

Teniendo en cuenta que la escritura tiene un peso relativamente bajo en el mundo del flamenco, resulta pertinente la pregunta de cuál es el texto que debe ser objeto de un análisis literario. Los estudios sobre la performance y lo performativo, aptos para acercarse a un fenómeno musical y a la vez poético como es el flamenco, subrayan la necesidad de considerar los textos literarios en su puesta en escena ${ }^{4}$. En consecuencia, el objeto de estudio solo puede ser el texto emitido en una ocasión determinada, en el evento concreto bic et nunc, por lo que se trata de un texto en alto grado efímero.

También la revista Litoral (Ropero y Cenizo 2004) dedica un número especial a la poesía del flamenco. Desde una perspectiva enfocada en su creación literaria por un autor, Cenizo (2004a) distingue la poesía en cuestión básicamente en coplas flamencas como producción, por un lado, y poesía flamenca como reflejo, por otro lado. Mientras que el primer término hace referencia a las letras creadas realmente para que se canten, la segunda expresión describe la poesía escrita sobre un motivo flamenco, para ser leída, sin seguir necesariamente la meta de ser usada como soporte literario en un cante. Estas definiciones básicas suelen ser aplicadas en la mayoría de las investigaciones recientes sobre la poesía del cante.

Sin embargo, teniendo en consideración que se trata de una poesía oral efectivamente entonada, se puede deducir también la necesidad de examinar los textos cantados de viva voz por un cantaor ${ }^{5}$, en su performance puntual.

En cuanto a este asunto, hay que admitir que pocas veces se ha recurrido a la forma en la que los textos realmente son cantados; algunas excepciones constituyen las tesis de González (2015) o Martín (2016), que

3. Muchas aportaciones científicas recientes son frutos de tesis doctorales, realizadas o bien en un programa de doctorado de la Universidad de Sevilla (desde 2004 a 2017) o bien en otros centros de investigación.

4. Con respecto a un texto poético, la performance queda definida por ZuMTHOR (1991, 34) como la operación compleja que abarca la transmisión y recepción del poema oral, en el momento en el que estas dos fases se realizan de forma simultánea, coincidiendo los emisores y los receptores involucrados en espacio y tiempo. Para el ámbito del teatro, FisCHER-LichTE (2011) destaca la importancia de la performance, ya que esta causa cierta autonomía de la realización de una obra artística: lo importante ya no es el texto escrito (fijo), sino su puesta en escena.

5. Es significativo que FERNÁNDEZ y PÉrEZ (2004, 24) apliquen el mismo criterio, el de haberse documentado «en la voz de uno de los grandes cantaores de estos últimos cien años», para incluir una copla en su colección. 
examinan varias letras completas de determinadas unidades de cantes. Pero todavía no queda resuelto si el concepto de coplas flamencas hace referencia exclusiva a cada estrofa aislada, como ente autónomo, o también al conjunto de las estrofas que emplea un cantaor como letras de su cante en una ocasión determinada y en un orden concreto. Hasta hoy en día esta segunda unidad literaria apenas se ha estudiado, por lo que incluso carece de una denominación: propongo para esta entidad el término de poema del cante (compuesto). Por ello, resulta necesario discutir la premisa extendida de que las letras flamencas no pueden narrar, causada por su consideración dominante como coplas líricas breves, y que siempre se combinan en un cante compuesto de forma absolutamente aislada, sin poder relacionarse.

Teniendo en cuenta que el romancero tradicional se considera una de las bases de las letras flamencas, es interesante preguntarse cómo se puede comprender que las letras del flamenco se consideran tan esencialmente breves y líricas si el género del que derivan, al menos en gran parte, se caracteriza por ser un género de poesía narrativa, surgido a su vez de los cantares épicos medievales.

Ordóñez $(2010,38)$ se centra también en el aspecto de la performance del cante y presenta una división de las coplas flamencas en tres etapas. La primera etapa corresponde a la composición de un prototipo de una copla, que es denominado copla de primera representación mental. La siguiente etapa ya es causada por la actuación del cantaor y corresponde a su adaptación del texto a los requisitos del palo flamenco que se interpreta, por lo que se denomina copla adaptada al palo. La tercera etapa es causada por la interpretación individual por cada cantaor, por lo que esta última se puede denominar la etapa de la copla con adornos propios.

La última etapa es la que resulta la más relevante para un análisis enfocado en el texto literario en su performance. De un examen de su forma textual concreta deriva la pregunta: ¿a nivel de texto literario, qué consecuencias tiene la actuación del cantaor sobre una copla flamenca?'.

Ordóñez observa además que «el intérprete es libre de escoger las coplas que va a cantar así como el orden en que vayan apareciendo» (2010, 34). Así, los cantaores se convierten en coautores del texto poético completo que surge gracias a su selección y reestructuración de las distintas estrofas breves, que enlazan en sus cantes. Así, centrándose en la situación

6. Hay que tener en cuenta que Ordóñez describe las transformaciones de las coplas que son causadas por aspectos musicales. Frente a esto, la investigación literaria se debe centrar ante todo en el texto, o sea, las modificaciones por las que se interesaría serían los casos en los que los cantaores añaden, recortan o sustituyen palabras por otras entre las distintas fases y cambian los valores semánticos del texto en sí. 
actual de las letras del cante, también resulta relevante la cuestión: ¿̇el texto literario que surge del encadenamiento de las distintas coplas por los cantaores, el mencionado poema del cante, puede tener una coherencia y narrar un relato?

Este nuevo texto de un cante completo es el que hasta hoy no está investigado, ya que la mayoría de las descripciones de la poesía flamenca se refieren a la copla breve, considerada emblemática para la poesía lírica.

\section{LA COPLA FLAMENCA SUELTA: LÍRICA Y BREVE}

Según la diferenciación de los géneros en literatura dramática (trágica), épica (narrativa) y poesía (lírica), la poesía se caracteriza por su brevedad e intimidad. En el siglo XIX, cuando cristalizó el flamenco, el paradigma de la subjetividad llegó a convertirse en una norma de interpretación (Brunke 2018, 33-52). Una de las consecuencias más visibles de esto es que la instancia del Yo lírico manifiesta su presencia de forma explícita en la mayoría de las coplas del cante, mientras que puede estar ausente en los géneros narrativos y en las baladas (Baltanás 2005, xxviii). En aquel momento, se relacionaban los géneros literarios con los aspectos de la vida extratextual que trataban, en el sentido de que la poesía lírica se consideraba la representación condensada de la autobiografía de un autor. En el caso de la poesía llamada popular, se atribuía la autoría de los poemas breves al colectivo denominado pueblo, por lo que fue considerada "la lírica como biografía del pueblo» (Baltanás 2005, xiii). Teniendo en consideración las modas del XIX y el correspondiente gusto por la lírica subjetiva, se puede comprender mejor por qué Demófilo publicó la mayoría de las letras recolectadas como coplas aisladas y breves.

Este modelo de los cancioneros marca la pauta que se sigue en la poesía del flamenco; las letras suelen existir para los flamencos a nivel de la "Copla suelta" (Gutiérrez 1990, 837). Estas coplas van asociadas además con determinados aspectos de naturaleza musical (Cruces 2004). Los poetas que añaden coplas a este acervo suelen publicarlas en sus libros también como poemas breves de cuatro o cinco versos.

Para explicar la forma aislada de publicar las coplas en su antología del folklore mexicano, Frenk (1976, xvii-xix) argumenta que estas coplas se asocian al azar y se pueden usar según melodías de canciones diferentes, siendo la melodía o la música el criterio que las convierte en canción. Así, los intérpretes pueden añadir las coplas en la canción a medida que van cantando, «echando versos sobre versos" (Frenk 1976, xviii), y no existe ningún orden definitivo. Este fenómeno se observa también en la 
«microcomposición del cante» (Cruces 2004, 600). ¿Esto significa que las letras, como poesía del cante, no pueden narrar en absoluto? Si se acepta que son frases absolutamente aisladas y solo casualmente combinadas, ¿pueden tener un sentido como texto literario? Además, si las coplas se considerasen meros testimonios autobiográficos de unos pocos individuos, habría que preguntarse si las letras en su conjunto pueden aportar algo a la memoria colectiva del flamenco.

Erll $(2012,197)$ considera a la literatura y a la poesía lírica en sí como formas simbólicas de la memoria colectiva de determinadas comunidades, estén estas constituidas por un país o por un grupo social. Esta filóloga, al presentar la literatura efectivamente como una puesta en escena simbólica de una cultura del recuerdo, señala varios puntos de intersección entre la memoria cultural y la literatura, de los que los dos principales son la condensación y la narración (Erll 2012, 198-202).

Con respecto al primer punto mencionado es relevante que las letras del cante, como poesía de tipo popular, contengan una "capacidad de expresar lo máximo con lo mínimo» (Gutiérrez 2007, 44). En las coplas sueltas del cante, los múltiples valores semánticos se centran de forma condensada en determinadas palabras clave. No obstante, estos valores semánticos solo se pueden detectar recurriendo al contexto de las letras. El contexto de la copla flamenca se genera por varios factores como, entre otros, la modalidad musical en la que se ejecuta, pero también por las otras coplas con las que se combina, formando estrofas en un poema compuesto. La combinación puntual de las coplas equivale al mencionado concepto de poema del cante.

Un factor con destacada relevancia tanto para la memoria como para la literatura y las letras del cante está constituido por el segundo punto de intersección: la narración y las estructuras narrativas. La memoria colectiva de una comunidad se expresa mediante unos procesos de narrar sobre el pasado, por lo que se puede equiparar a la literatura: "Cada remembranza consciente de la experiencia pasada que es relevante para una comunidad va acompañada de estrategias que también se utilizan en la constitución de textos literarios [...], (Erll 2012, 199). Muchas letras del cante flamenco proceden del romancero, género por definición narrativo, aunque cantado.

Para volver a la relación entre la memoria de un colectivo y los romances, resulta de especial interés que los textos, al incorporarse en el patrimonio de sus transmisores con las respectivas variantes, desde los antiguos cantos épicos de los héroes españoles, se convirtieron más bien en una nueva forma épica de los grupos sociales de los estratos bajos, que se identificaron con ellos. Un ejemplo de esto es la identificación que mantienen muchos gitanos con el personaje romancístico de Bernardo del Carpio 
(Suárez 1994). Muchos fragmentos de los romances del ciclo de Bernardo siguen siendo cantados en el flamenco sin que los intérpretes perciban que estos trozos formaban parte de romances más largos. De los romances se desgajan los diálogos u otras fórmulas y se usan como estrofas líricas condensadas. Estos procesos muestran de manera muy drástica el fragmentarismo y la ruptura en unidades mínimas, fenómenos omnipresentes en el flamenco, que propician la conversión en coplas sueltas.

En general, las versiones que han resultado de una transmisión activa y tradicional de los romances por los gitanos andaluces llaman la atención por su brevedad (Piñero 2013, 50). Por un lado, en estos romances corridos, los elementos fragmentados se han recompuesto de nuevo en unas composiciones mixtas para poder volver a narrar. Este mecanismo explica por qué las versiones de romances recogidas de transmisores gitanos son tan heterogéneas. Por otro lado, Suárez Ávila $(2008,6)$ declara que los muchos fragmentos romancísticos mencionados, que se emplean en varios palos del flamenco, se han convertido en no romances. Se hace notar esto, sobre todo, en muchas coplas típicas de las bulerías.

Con respecto a su investigación sobre la tradición romancística entre gitanos jerezanos, Bonet y Ruiz $(1989,639)$ constatan que sus informantes flamencos no solían cantar conscientemente los romances de forma corri$\mathrm{da}$, por lo que muchos textos que han podido recoger estas investigadoras consisten en fragmentos independizados y cantados por bulerías. Debido a la subordinación del texto literario a la música, se suele sacrificar el relato y las coplas sueltas se engarzan con fragmentos de otras procedencias. Baltanás y Pérez $(1989,628)$ llegan a los mismos resultados e indican que, en casos normales, «el romance se fragmenta en cuartetas aisladas, facilitando su interpretación en el compás de la bulería». Al enlazar los distintos fragmentos durante el cante, surge un texto nuevo y difícil de definir como romance, o sea, un collage sumamente híbrido de múltiples elementos.

Suárez Ávila $(2008$, 6) explica que «es preciso conocer a fondo el romancero oral, para sorprender, en medio de una serie de bulerías por soleá, o en medio de unas letras de tonás, fragmentos, que, trasegados en la tradición, se han convertido en otra cosa». Esta otra cosa es lo que se suele llamar copla flamenca, la unidad aislada. En el caso de encastrar los fragmentos en una serie de algún palo o estilo flamenco, un cantaor ya no sabe que está transmitiendo romances y solo se refiere a la performance musical sin poder definir el texto literario, es decir que "no tiene más noción que lo que está haciendo es cantar por bulerías, por soleá o por tonás» (Suárez 2010, 302).

La relación entre romancero y flamenco es más evidente en el caso de ciertos cantes a palo seco, como son las tonás o los martinetes (véase Homann en prensa). En estas modalidades básicas del flamenco, los cantaores 
suelen emplear fragmentos de antiguos romances (Campo y Cáceres 2013, 461). Zoido (1999, 195-208) concluye que un gran número de las letras de estos palos, atribuidas a transmisores gitanos, provienen de fragmentos de unos textos orales baladísticos más largos, que se han compuesto para dar cuenta de los hechos trágicos en el marco de la Prisión General o Gran Redada de los Gitanos en 1749, acontecimiento poco conocido hasta una fecha relativamente reciente. Suárez Ávila reafirma esto en diversos escritos y proporciona muchos testimonios de tonás cantadas por sus informantes para resumir que estas constituyen una verdadera épica de los gitanos bajoandaluces. También Caballero Bonald $(2004,587)$ hace una observación que corrobora lo dicho sobre una posible narratividad anterior de estos cantes: «A veces, como en las viejas tonás, se tiene la impresión de que lo que oímos es prosa cantada". Con respecto a la relación entre romances y coplas flamencas en la actualidad, Zoido (2004, 649) se expresa así: «Sin ser conscientes de ello, las voces de los cantaores desgranan aún muchas estrofas que la fragilidad de la memoria desgajó de un corpus inmenso y que convirtieron en coplas independientes las veleidades de las modas».

Para explicar la transformación de este tipo específico de poesía oral hasta el estado actual de coplas aisladas, se puede argumentar que la brevedad de las coplas y el paradigma de subjetividad del Yo lírico son causados mayoritariamente por las modas del siglo XIX. La cultura flamenca, surgida en esta época, sigue a estas corrientes estéticas dieciochescas, por lo que estas constituyen también un factor importante que determina la forma de las letras flamencas. Y es que la forma exterior en la que los textos se han conservado depende de cómo los transcribieron sus recopiladores, que en su mayoría optaron por la copla suelta y lírica, en boga en aquel entonces. Hay que anotar que Demófilo publicó sus martinetes en dos apartados: uno contiene las coplas aisladas, mientras que el otro apartado contiene lo que él llamó trovos, que se pueden definir como relatos coherentes de varias estrofas. En su momento de recopilación, en la segunda mitad del siglo XIX, estos trovos ya se encontraban en un estado de extrema reducción, que se debe haber realizado en los más de cien años que pasaron desde que se produjeron los hechos despiadados de la Gran Redada. Así, se puede suponer en muchos casos que ya en el momento de recopilar Demófilo las letras ni los mismos transmisores eran realmente conscientes de qué contenido exacto transportaban los textos cantados por ellos. En relación con esto se encuentra además el hecho de que la política oficial ocultaba ya a finales del siglo XVIII este intento de un verdadero genocidio (Martínez 1999). Al fragmentarse los textos, se ha olvidado el evento concreto de la Gran Redada.

Si aceptamos estas premisas, podemos asegurar que las tonás y los martinetes existirían ya desde hace tiempo, con la diferencia de que 
anteriormente al siglo XIX no eran modalidades del flamenco -que aún no existía-, sino romances largos y narrativos, recitados en su mayoría por transmisores gitanos.

Esto tiene consecuencias para acercarse al flamenco de los siglos xx y XXI. Si admitimos que existe una relación entre estos cantes a palo seco y las narraciones largas en forma de romances congruentes sobre los contenidos de la memoria colectiva de ciertos grupos sociales, podemos entender mejor por qué Moreno Galván quiso recuperar y hacer revivir este género en sus letras para José Menese. El texto que este cantaor pone en escena por martinetes sobre el asesinato del personaje ficticio Juan García es de hecho un romance coherente, que se guía en extraordinaria medida por las fórmulas de las múltiples coplas tradicionales que se entonan en la correspondiente música (Martín 2016, 115).

Moreno Galván intuía también que se usaba con frecuencia la décima en las letras del cante temprano. En el capítulo 46 de Rito y geografía del cante, el poeta explica que los tangos del Piyayo empleaban esta estrofa narrativa de diez versos. No obstante, el fragmentarismo omnipresente en el cante ha causado que estas letras se consideren hoy coplas breves de, normalmente, cuatro versos. Este hecho queda demostrado por Soler (2012, 84), quien aclara cómo el cantaor malagueño el Piyayo trajo las décimas desde Cuba, donde se cantaban entre la población campesina. Moreno Galván compuso unas letras coherentes, basadas en varias estrofas relacionadas de décimas, con un profundo contenido social, para estos tangos que cantaba Menese.

En resumen, frente a la consideración dominante de la copla suelta, sostengo que muchas letras flamencas, en un estado anterior, constituían narraciones más extensas que se han ido fragmentando; en otras palabras, muchas coplas sueltas formaban parte de poemas largos narrativos. No obstante, hoy se ha olvidado por lo común que la poesía del flamenco también narraba. Debido a este olvido, tampoco hay un gran interés en examinar el resultado de haber enlazado un intérprete cantaor varias estrofas en una unidad de cante, por lo que este artículo pretende, ante todo, cuestionar la presuposición de que en las letras del flamenco no existe ninguna relación interestrófica.

\section{LOS NUEVOS COLLAGES DE LETRAS EN EL CANTE}

La distinción de Cenizo entre copla flamenca como producción y poesía flamenca como reflejo hace referencia a la poesía desde el punto de partida de su creación por un autor. Sin embargo, el flamenco se emite vía 
oral y los que emiten esta poesía son los cantaores, instancias centrales. Según el concepto de poesía tradicional de Menéndez Pidal, cada transmisor es un coautor. Considerando este hecho, surge un producto literario nuevo, generado por la microcomposición del cantaor en su puesta en escena de varios elementos elegidos. Así, a las dos categorías de Cenizo, sin duda útiles, creo conveniente añadir una tercera que es el poema del cante.

Los poetas que componen coplas para los cantaores les dan la posibilidad de reordenar las estrofas según ellos quieren. Un ejemplo de esto son las coplas de cantes de trilla que ha compuesto el propio Cenizo y su realización por Calixto Sánchez. Entre la publicación por escrito en un libro (Cenizo 2007, 54-55) y el texto que ha grabado el cantaor para el disco del número especial de Litoral se notan las diferencias en el orden de las coplas. En esta línea, el poeta deja clara la necesidad de que las coplas se hagan suyas y se modifiquen por el cantaor en su función de coautor, última y más importante instancia de emisión, a la hora de cantarlas: "Las letras, al pasar al cante, pueden -incluso deben- sufrir alguna transformación, a gusto del cantaor» (Cenizo 2004b, 308). A pesar de constituir cada copla, en principio, una manifestación lírica completa e independiente, el producto de un cante -en el sentido de pieza musical- establece una relación entre las coplas insertadas, al menos esto puede ser la impresión que se da al receptor. Más allá de la producción de nuevas letras, esto se puede observar también con respecto a las letras tradicionales. Si consideramos el conjunto de las estrofas que emplea un cantaor en una ocasión de performance determinada, llegamos a detectar en muchos casos una relación entre los distintos elementos enlazados en su orden concreto: incluso se pueden encontrar algunos relatos coherentes. En esta línea, Piñero (2010, 329) subraya las ventajas de anotar la ordenación de las coplas y una transcripción de la unidad entera para interpretar sus valores semánticos de forma adecuada: «El filólogo debe estudiarla en su puntual performance para captar y señalar todo su sentido y analizar sus elementos dentro de un sistema, el que el cantor ha conseguido en su recreación determinada». En cualquier caso, hay que anotar que en la microcomposición del cante, según el enlazamiento de varias coplas, estas no suelen seguir un orden definitivo, por lo que el poema oral que resulta es en alto grado efímero. En consecuencia, habrá que cuestionar también si una copla tiene un sentido fijo o, al contrario, ofrece una multitud de significados posibles, que dependen en gran medida del contexto en que se inserta cada estrofa.

En general, las coplas pueden saltar entre los distintos palos y estilos flamencos. Unas mínimas modificaciones de palabras para adaptarlas pueden provocar considerables cambios en los significados de las coplas, con respecto a la interpretación literaria. 
En cuanto a la clasificación de una copla, los saltos entre las modalidades musicales además pueden generar diversas confusiones. Existen clasificaciones cuyos criterios se basan en los aspectos literarios de una estrofa, lo que provoca una nueva complejidad. Por un lado, las coplas se pueden llamar según el palo en que se suelen emplear; por otro lado, se puede denominar a una forma métrica con el mismo nombre que lleva un palo flamenco determinado: el término seguiriya se puede usar para denominar una modalidad flamenca musical y una forma estrófica que también se denomina seguidilla flamenca (Quilis 1996, 101). El mismo reto de definición surge con respecto a la soleá, palabra que puede denominar el palo flamenco y una estrofa de tres versos de ocho sílabas. Para la forma estrófica, se ofrece la denominación terceta (octosilábica). Si trabajamos con rigor, una estrofa literaria solo se convierte en seguiriya o soleá gracias a su puesta en escena, en la modalidad musical correspondiente.

Debido a que Demófilo llamó a la extensión de la terceta «soleá de cuatro versos", en su colección se encuentran 71 ejemplos de tiranas -las arquetípicas cuartetas romanceadas de ocho sílabas- que figuran como soleares. No obstante, no siempre queda comprobado si estas estrofas realmente merecen ser llamadas así, ya que no consta si efectivamente se han cantado en la modalidad flamenca del mismo nombre. Un ejemplo famoso es la siguiente copla (Machado 1996, 177):

\section{En er carro e los muertos \\ Ayer pasó por aquí, \\ Yebaba la mano fuera... \\ Por eya la conosí.}

Hay consenso en que esta copla se suele entonar, en la mayoría de los casos, por seguiriyas. Ventura Ruiz Aguilera (1866, 249) dijo que la cuarteta "es un fragmento de un romance, que asimismo pasa por vulgar, y cuyo título siento no recordar [...]». Si le damos la razón a este poeta, hay que reafirmar que ciertos fragmentos de tres o cuatro versos se pueden independizar de un romance y obtener un sentido propio. Estos elementos contienen una alta carga simbólica que los convierte en atractivos para los cantaores. Suárez Ávila $(2010,301)$ comenta: "De ahí que haya fragmentos romancísticos de cuatro versos incrustados en una serie de coplas, con cierto sentido propio, que se han llevado a un plano modélico, se han ritualizado o han sido considerados dignos de permanecer y ser imitados por su valor paradigmático».

Reyes $(2010,268)$ está convencido de la "clara procedencia romanceril» del ejemplo presentado. Si admitimos que esta estrofa bien puede ser otro fragmento de un romance anterior, llegamos al resultado de que, en su 
origen, muchas coplas no se han compuesto, como es el caso hoy, para los distintos palos, sino que han derivado de otros poemas orales, que a su vez se han entonado según distintas músicas. Gracias a su alto valor simbólico, estas coplas densas y breves siguen en uso.

Lo que resulta evidente es que, en la poesía oral, forma definitiva no hay: no se trata de textos acabados y cerrados, sino de elementos que se pueden retomar por diversos emisores y que son continuamente modificables, en la cadena de tradición oral. En resumen, son los cantaores quienes dan a los textos su forma concreta. En consecuencia, los valores semánticos de una copla en un momento concreto se pueden conocer solo si consideramos su contexto. El contexto inmediato del texto romancístico se perdió a la hora de independizarse el fragmento mencionado.

Gustavo A. Bécquer usó la copla que arriba hemos transcrito en el final trágico de su relato "La venta de los gatos» y la pone en la boca del joven protagonista para lamentar la muerte de su amante. Es llamativo que la copla en sí no contiene indicios de a quién se refiere y esta referencia se puede deducir solo del texto que aparece a continuación en el relato.

En cuanto a su empleo en el cante, el contexto de la estrofa se puede determinar por las otras estrofas con las que se combina la copla. El cantaor José de los Camarones incrustó la estrofa como tercera unidad en una serie por seguiriyas, cantada el 30 de abril de 2017 en Jerez de la Frontera. En su conjunto, sus seguiriyas se componen de cuatro coplas autónomas muy conocidas entre los flamencos y recitadas con frecuencia en esta modalidad. Lo que hace el cantaor en la performance concreta es unirlas y ordenarlas para reinterpretarlas y recrearlas en su cante compuesto. Se puede decir que son coplas cuyo contenido literario indica la misma dirección interpretativa, por lo que la reordenación musical llega, a nivel literario, a una actitud de vincular los elementos sueltos de campos semánticos cercanos. En la interpretación, se puede cerrar un círculo temático lógico.

Las primeras dos coplas empleadas, en su estado de copla con adornos propios, y cuyos prototipos se encuentran en la colección de Fernández Bañuls y Pérez Orozco (2004, 239 y 182), dan cuenta de un desconsuelo extremo del Yo lírico, sin explicar por qué razones está causado. La tercera estrofa, la del carro de los muertos, descifra esto al describir cómo el Yo lírico se vio extremadamente impactado por el descubrimiento de la muerte de una figura femenina conocida. Para poder interpretar quién es esta figura, la cuarta estrofa resulta clave:

Compadrito mío Cuco,

¡Anda, ve y dile a mi madre:

Que la encuentro en esa casapuerta

-Ay- revolcadito en sangre! 
Esta última estrofa constituye otra copla conocida y ejecutada frecuentemente en las seguiriyas, a pesar de que probablemente procede también de un texto más largo. En esta ocasión, se modifican varias palabras de una seguidilla flamenca que se encuentra en Fernández Bañuls y Pérez Orozco (2004, 202):

\author{
Hermanito Cuco \\ Dile a mi madre \\ Que yo me muero en esta casapuerta \\ Revolcado en sangre.
}

La copla cuenta con una considerable popularidad en el mundo del cante y se relaciona con una manera particular de cantar las seguiriyas en Jerez. Debido a su empleo frecuente en distintas variantes, se ha convertido la casapuerta -elemento presente en todas las versiones- en lugar común de la muerte.

La referencia a la figura del Cuco es también omnipresente en las versiones flamencas. Esta copla puede ser extraída de un relato oral sobre la muerte de José Gómez Ortega, Joselito el Gallo, en 1920. En este contexto resulta llamativo que Suárez Ávila $(2004,6)$ mencione una versión romancística sobre la muerte del torero, procedente de un pliego de cordel y cantada por Geroma la del Planchero. En las bulerías a Joselito que canta Camarón de la Isla en el capítulo 74 de Rito y geografía del cante, el texto del relato coherente da cuenta de que el protagonista herido, después de haberlo llevado al hospital, «le dice a su primo el Cuco: ¡Cuco suéltame la mano que mi fatiga es muy grande y no me llego ni a las heridas!». Enrique Ortega Fernández llevaba el apodo del Cuco y acompañaba como banderillero al famoso torero gitano. En el relato por bulerías no se incluye la cuarteta concreta; sin embargo, no carece de sentido que esta se haya desprendido también de un cantar narrativo, considerando que esta copla puede constituir perfectamente el enlace de una historia sobre los últimos momentos de la vida del torero. Sin embargo, dado el caso de que se suele cantar la copla oral de forma aislada, estos son solo indicios sobre de dónde podría proceder la estrofa. El cantaor de la versión concreta modifica el texto ligeramente, por lo que el Yo lírico no declara explícitamente que se muere, sino que encuentra a su madre en esta casapuerta. En relación con lo anteriormente expuesto, se puede interpretar esto en el sentido de que el reencuentro con la madre en la metafórica casapuerta, con sus connotaciones de un lugar relacionado con la muerte, significa que la figura femenina muerta, hasta ahora anónima, es la madre del Yo lírico y que el mismo Yo, como voz del poema, también espera su propia muerte para alcanzar este reencuentro. Lo que posibilita esta interpretación del texto en conjunto es 
la temática arquetípica y trágica de las seguiriyas, que tratan con preferencia sobre la desolación causada por un fallecimiento, en concreto, el de la madre. Existen diversos ejemplos de coplas sueltas que hablan de este asunto (Cenizo 2005, 125-130).

Aunque la reordenación de las coplas se determina, en primer lugar, por las exigencias musicales, este cantaor jerezano también actúa, de hecho, sobre el texto literario, ya que él emite las letras de esta forma puntual. En este sentido, toma la decisión de enhebrar las distintas coplas en este orden: esta decisión, a su vez, influye en el texto literario que surge en la performance. Así, no es menospreciable trabajar con una nueva relación, surgida a nivel de poema entero, que efectivamente narra. Ya decía Federico García Lorca en su conferencia «Importancia histórica y artística del primitivo canto andaluz llamado cante jondo" que "llega el cante jondo, pero especialmente la siguiriya, a producirnos la impresión de una prosa cantada, [...] aunque en realidad son tercetos o cuartetos asonantados sus textos literarios" $(1984,56-57)$. De hecho, las letras pueden transmitir un relato coherente a un receptor que las perciba de esta manera. La consiguiente relación entre los elementos es también causada por la manera de cantarlos en un único cante, con principio y fin marcado a nivel musical. Se puede hablar, por tanto, de un verdadero poema del cante.

En resumen, existen unas premisas cimentadas en el discurso del flamenco de que cada copla es esencialmente lírica y personal; sin embargo, estas ideas hay que ubicarlas como constructos en el panorama de las modas del XIX, siglo de la cristalización de la cultura flamenca. Muchas coplas derivan de una poesía anterior, es decir, son fragmentos de otros poemas narrativos y más largos. Durante mucho tiempo, los involucrados en el cante han prestado poco interés a la secuencialidad de las coplas a nivel literario. No obstante, varios letristas actuales sí tienen en cuenta estos factores y quieren narrar algo con sus soportes literarios, creados para el cante.

Además, en la performance del cante flamenco ocurre un fenómeno interesante: surge un nuevo texto literario y efímero, ya que los cantaores combinan varias coplas, que en su conjunto se pueden recibir como un relato. Aunque no siempre este relato tiene que ser intencionado, conviene comprobar si existe una relación temática entre las distintas estrofas empleadas. Estas estrofas a las que recurren los cantaores para construir sus cantes pueden saltar entre los distintos palos y estilos del flamenco y, por lo tanto, entre distintos contextos. Así, las coplas no tienen una forma y un sentido definitivo, ya que continuamente se encuentran en movimiento, modificándose en la oralidad del cante: ni las grabaciones han parado estas dinámicas, dado que muchos cantaores emplean las coplas antiguas, reordenando y recontextualizándolas en sus combinaciones 
nuevas. En consecuencia, los valores semánticos de las coplas pueden variar notablemente.

En definitiva, los cantaores son los que determinan qué es lo que transporta el texto que emiten. Pueden darles a sus letras un sentido como texto narrativo y con su nueva reorganización de coplas antiguas pueden aportar su punto de vista a la memoria colectiva del flamenco.

\section{Bibliografía}

Baltanás, Enrique. «Introducción». En Rodríguez Marín, Francisco. Cantos populares españoles. Sevilla: Renacimiento, 2005, pp. IX-XXXIV.

Baltanás, Enrique y Antonio Pérez Castellano. «Cómo vive el romancero entre los gitanos de la provincia de Sevilla: Las familias Peña y Fernández». En PIÑERO, Pedro et al. (eds.). El Romancero: Tradición y pervivencia a fines del siglo XX. Sevilla/Cádiz: Fundación Machado/Universidad de Cádiz, 1989, pp. 625-636.

Bonet, Soledad y María Jesús Ruiz Fernández. «Unas calas en los romances de los gitanos de Jerez». En PIÑERO, Pedro et al. (eds.). El Romancero: Tradición y pervivencia a fines del siglo XX. Sevilla/Cádiz: Fundación Machado/Universidad de Cádiz, 1989, pp. 637-645.

BRunke, Dirk. Das romantische Epos am Río de la Plata: Subjektivität und Lyrisierung. Stuttgart: Steiner, 2018.

CABAlLERO Bonald, José Manuel. «Copla flamenca: fuentes cultas y populares». En Piñero, Pedro y Antonio Pérez Castellano (eds.). De la canción de amor medieval a las soleares: Profesor Manuel Alvar in memoriam. Sevilla: Fundación Machado, 2004, pp. 581-587.

CAMPO TEJEDOR, Alberto del y Rafael CÁCERES FERIA. «Herreros y Cantaores: El trabajo de los metales en la génesis del flamencom. Revista de Dialectología y Tradiciones Populares, 2013, vol. LXVIII, n. ${ }^{\circ} 2$, pp. 445-467.

Cenizo, José. «Poesía flamenca y copla flamenca: una distinción necesaria». Litoral, 2004a, 238, pp. 32-38.

Cenizo, José. «La historia de una gran emoción». Litoral, 2004b, 238, p. 308.

CENIZO, José. La madre y la compañera en las coplas flamencas. Sevilla: Signatura, 2005.

Cenizo, José. Con pocas palabras. Sevilla: Signatura, 2007.

CRuces Roldén, Cristina. "Decir el cante: la lírica popular al servicio de la música flamenca». En Piñero, Pedro y Antonio Pérez CASTEllano (eds.). De la canción de amor medieval a las soleares: Profesor Manuel Alvar in memoriam. Sevilla: Fundación Machado, 2004, pp. 599-612.

ERLL, Astrid. Memoria colectiva y culturas del recuerdo: estudio introductorio. Trad. por Johanna Córdoba y Tatjana Louis. Bogotá: Universidad de los Andes, 2012.

FERNÁNDEZ BaÑuls, Juan y José Pérez OROZCo. La poesía flamenca, lírica en andaluz. Segunda edición. Sevilla: Signatura, 2004. 
FisCHER-LichTE, Erika. Estética de lo performativo. Trad. por Diana González Martín y David Martínez Perucha. Madrid: Abada, 2011.

Frenk, Margit. Prólogo a Frenk, Margit (ed.). Cancionero folklórico de México. Tomo 1: Coplas del amor feliz. México: El Colegio de México, 1976, pp. xv-xlvi.

García LorCA, Federico. Conferencias I. Editado por Christopher Maurer. Madrid: Alianza, 1984.

GONZÁLEZ SÁNCHEZ, Carmen. La recepción de Miguel Hernández en la música flamenca: estudio de literatura comparada. Tesis doctoral. Universidad de Sevilla, 2016. https://idus.us.es/xmlui/handle/11441/39813 [1 de diciembre de 2019].

GutiérRez CARBAjo, Francisco. La copla flamenca y la lírica de tipo popular. Tomo II. Madrid: Cinterco, 1990.

Gutiérrez CARBajo, Francisco. La poesía del flamenco. Córdoba: Almuzara, 2007.

Homann, Florian. "Las letras primitivas de los cantes a palo seco, tonás y martinetes: romances narrativos sobre la Prisión General de los Gitanos». Cultura, Lenguaje y Representación, en prensa, 2020, vol. 24.

MACHADO y Álvarez, Antonio. Colección de cantes flamencos: Recogidos y anotados por Demófilo. Editado por Enrique Baltanás. Sevilla: Portada, 1996.

MarTín CABEZA, Juan Diego. La obra literaria y pictórica de Francisco Moreno Galván: Estética, compromiso y cultura popular. Tesis doctoral. Universidad de Sevilla, 2016. https://idus.us.es/xmlui/handle/11441/33168 [1 de diciembre de 2019].

MARTínez Martínez, Manuel. "Los centenarios olvidados: V Centenario de la Pragmática de Medina del Campo y 250 Aniversario de la Redada General de Gitanos». O Tchatchipen: lil ada trin tchona rodipen romani, 1999, 26, pp. 24-27.

Molina, Ricardo y Antonio Mairena. Mundo y formas del cante flamenco. Editado por José Cenizo. Sevilla: Giralda, 2004.

ORDÓÑEz FlORES, Eva. "Estructuras subyacentes a la copla flamenca y figuras literarias de variaciones". Ogigia: Revista Electrónica de Estudios Hispánicos, 2010, 8, pp. 33-45. https://dialnet.unirioja.es/servlet/articulo?codigo=3253739 [1 de diciembre de 2019].

PiÑERO, Pedro. «Presentación». En PiÑERO, Pedro y Antonio Pérez Castellano (eds.). De la canción de amor medieval a las soleares: Profesor Manuel Alvar in memoriam. Sevilla: Fundación Machado, 2004, pp. 7-12.

PIÑERO, Pedro. La niña y el mar: Formas, temas y motivos tradicionales en el cancionero hispánico moderno. Madrid/Frankfurt: Iberoamericana/Vervuert, 2010.

Piñero, Pedro. "Historia de la investigación». En PiÑERO, Pedro (ed.). Romancero de la provincia de Sevilla. Sevilla: Universidad de Sevilla, 2013, pp. 19-72.

Quilis, Antonio. Métrica española. 9. ${ }^{a}$ edición. Barcelona: Ariel, 1996.

Reyes Cano, Rogelio. "Bécquer y el mundo del flamenco». Boletín de la Real Academia Sevillana de Buenas Letras: Minervae Baeticae, 2010, 38, pp. 267-288.

Ropero NúÑEz, Miguel y José Cenizo Jiménez (coords.). "La poesía del flamenco». Número especial con CD. Litoral, 2004, 238.

Ruiz Aguilera, Ventura. "Sobre la colección de cantares atribuidos al vulgo». Revista Hispano-Americana, 27 noviembre de 1866, pp. 246-254. 
SOlER DíAz, Ramón. «La poesía de tradición oral en Málaga: antecedentes y devenir contemporáneo». Música Oral del Sur, 2012, 9, pp. 70-101.

SteIngress, Gerhard. Sociología del cante flamenco. Jerez: Centro Andaluz de Flamenco, 1993.

SuÁrez Ávila, Luis. "El romancero de los gitanos, germen del cante flamenco». En PIÑERO, Pedro et al. (eds.). El Romancero: Tradición y pervivencia a fines del siglo XX. Sevilla/Cádiz: Fundación Machado/Universidad de Cádiz, 1989, pp. 563-608.

SuÁrez Ávila, Luis. «De Bernardo del Carpio a los gitanos bajoandaluces». Ínsula: Revista de Letras y Ciencias Humanas, 1994, 567, pp. 18-20.

SuÁrez Ávila, Luis. "Jaleos, gilianas, versus bulerías». Revista de Flamencología, 2004, 20, pp. 3-18.

SuÁrez Ávila, Luis. «Flamenco: motivación metonímica y evolución cultural del nombre de los gitanos y de su cante». Culturas Populares: Revista Electrónica, 2008, 7, pp. 1-26. http://www.culturaspopulares.org/textos7/articulos/suarez. htm [1 de diciembre de 2019].

SuÁrez Ávila, Luis. "La memoria viva, el olvido y el fragmentismo, poderosos agentes fundacionales del flamenco". Boletín de la Real Academia Sevillana de Buenas Letras: Minervae Baeticae, 2010, 38, pp. 289-314.

Vergillos, Juan. Conocer el flamenco: Sus estilos, su historia. Sevilla: Signatura, 2002.

ZoIDO, Antonio. La prisión general de los gitanos y los orígenes de lo flamenco. Mairena del Aljarafe: Portada, 1999.

ZoIDO, Antonio. "Badulaques, soldados, negros, gitanos... y flamencos: la poesía popular y el origen del término flamenco». En PIÑERO, Pedro y Antonio PÉREZ Castellano (eds.). De la canción de amor medieval a las soleares: Profesor Manuel Alvar in memoriam. Sevilla: Fundación Machado, 2004, pp. 649-656.

ZumThor, Paul. Introducción a la poesía oral. Trad. por Concepción García-Lomas. Madrid: Taurus Humanidades, 1991. 